\title{
Maestría en Geografía
}

\section{Relación de estudiantes de las promociones XVI y XVII}

\begin{tabular}{|c|c|}
\hline Promoción XVI & Promoción XVII \\
\hline $\begin{array}{l}\text { CIFUENTES CONTRERAS GERMÁN } \\
\text { Ingeniero Catastral y Geodesta }\end{array}$ & $\begin{array}{l}\text { BEDOYA PRADO ALEXANDRA } \\
\text { Lic. en Ciencias Sociales y Económicas }\end{array}$ \\
\hline DELGADO LILIANA CLAUDIA & CASTRO ORTEGA CARLOS HERNÁN \\
\hline 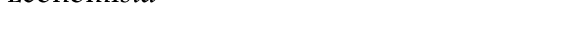 & \\
\hline $\begin{array}{l}\text { DUQUINO ROJAS LUIS GABRIEL } \\
\text { Arquitecto }\end{array}$ & $\begin{array}{l}\text { HERNÁNDEZ NELCY AZUCENA } \\
\text { Ingeniera Catastral y Geodesta }\end{array}$ \\
\hline $\begin{array}{l}\text { FONSECA FINO FELIPE } \\
\text { Ingeniero Forestal }\end{array}$ & $\begin{array}{l}\text { HERRERA SÁNCHEZ MARCO TULIO } \\
\text { Ingeniero Geógrafo }\end{array}$ \\
\hline $\begin{array}{l}\text { LÓPEZ CASTRO CHARLES ALFONSO } \\
\text { Ingeniero Catastral y Geodesta }\end{array}$ & $\begin{array}{l}\text { INFANTAS BARBACHÁN EDGAR IVÁN } \\
\text { Ingeniero Geógrafo }\end{array}$ \\
\hline $\begin{array}{l}\text { GÓMEZ CONTRERAS LUZ MERY } \\
\text { Ingeniera Catastral y Geodesta }\end{array}$ & $\begin{array}{l}\text { MENDOZA PADILLA BETTY } \\
\text { Arquitecta }\end{array}$ \\
\hline $\begin{array}{l}\text { GONZÁLEZ CUBILLOS ROBERTO } \\
\text { Lic. en Ciencias Sociales y Económicas }\end{array}$ & $\begin{array}{l}\text { MURILLO MUNAR SONIA JIMENA } \\
\text { Arquitecta }\end{array}$ \\
\hline $\begin{array}{l}\text { LLANOS HENRIQUEZ EFRAÍN } \\
\text { Lic. en Ciencias Sociales y Económicas }\end{array}$ & $\begin{array}{l}\text { NARVÁEZ CÓRDOBA EDILBERTO } \\
\text { Sociólogo }\end{array}$ \\
\hline $\begin{array}{l}\text { MAYA HERRERA MARÍA DEL PILAR } \\
\text { Administradora Pública }\end{array}$ & $\begin{array}{l}\text { PADILLA SALAZAR ADOLFO } \\
\text { Ingeniero Geógrafo }\end{array}$ \\
\hline $\begin{array}{l}\text { ONTIVEROS VÁSQUEZ ROGELIO RUFINO } \\
\text { Lic. en Geografía y Ciencias de la Tierra }\end{array}$ & $\begin{array}{l}\text { ROMERO NOVOA JORGE ALESSANDRI } \\
\text { Ingeniero Catastral y Geodesta }\end{array}$ \\
\hline $\begin{array}{l}\text { PEÑUELA CLAVIJO LIBIA ESPERANZA } \\
\text { Ingeniera Catastral y Geodesta }\end{array}$ & $\begin{array}{l}\text { RUBIANO RUBIANO JUAN CARLOS } \\
\text { Economista }\end{array}$ \\
\hline $\begin{array}{l}\text { SERRATO ÁLVAREZ PEDRO KARÍN } \\
\text { Agrólogo }\end{array}$ & $\begin{array}{l}\text { SÁNCHEZ MARIÑO ADELIA HASLEIDY } \\
\text { Lic. en Ciencias Sociales }\end{array}$ \\
\hline $\begin{array}{l}\text { TRIANA GARCÍA JOSÉ VILLE } \\
\text { Arquitecto }\end{array}$ & \\
\hline
\end{tabular}

Perspectiva Geográfica Núm. 11, 2005 331 